\title{
Effect of Additions of Organic Sulfonates on the Conductivity of Lithium Conducting Polymer Electrolytes
}

\author{
Zhumabay BAKENOV, Hiromasa IKUTA, and Masataka WAKIHARA*
}

\begin{abstract}
Department of Applied Chemistry, Graduate School of Science and Engineering, Tokyo Institute of Technology (2-12 1, O-okayama, Meguro-ku, Tokyo 152-8552, Japan)
\end{abstract}

\author{
Received September 1, 2000 ; Accepted February 7, 2001
}

\begin{abstract}
The electrochemical properties of the solid polymer electrolytes (SPE) containing lithium trifluoromethanesulfon imide (LiTFSI) and novel lithium sulfonates have been investigated. Sulfonates as additives into the LiTFSI-based SPE showed ionic conductivities up to $5.1 \times 10^{-4} \mathrm{~S} \cdot \mathrm{cm}^{-1}$ at room temperature. Improvement of the ionic conductivity is attributed to the formation of the coordination centers in the system and an increase of amorphous degree of the SPE.
\end{abstract}

Key Words: Lithium Ion Batteries, Solid Polymer Electrolytes, Lithium Ion Conductivity, Lithium Organic Sulfonate

\section{Introduction}

Last decades have shown that a solution of the safety and cycleability problems of lithium ion batteries is possible by using solid polymer electrolytes (SPE). ${ }^{1}$ It has been reported that polyethylene oxide based $\mathrm{SPE}$ showed high conductivity up to $10^{-4} \mathrm{~S} \cdot \mathrm{cm}^{-1}$ at room temperature and good cycleability up to 1000 charge/discharge cycles were achieved. ${ }^{21}$

In our laboratory a new dry solid polymer electrolyte (DSPE) composed of polyethylene glycol based copolymer $\mathrm{CH}_{2}=\mathrm{C}\left(\mathrm{CH}_{3}\right) \mathrm{COO}\left(\mathrm{CH}_{2} \mathrm{CH}_{2} \mathrm{O}\right){ }_{90} \mathrm{CH}_{3}(\mathrm{PME}-4000)$, $\mathrm{CH}_{2}=\mathrm{C}\left(\mathrm{CH}_{3}\right) \mathrm{COO}-\left(\mathrm{CH}_{2} \mathrm{CH}_{2} \mathrm{O}\right)_{13} \mathrm{COC}\left(\mathrm{CH}_{3}\right)=\mathrm{CH}_{2}(\mathrm{PDE}-$ $600)$, borate ester polymer $\left(\mathrm{CH}_{3} \mathrm{O}\left(\mathrm{CH}_{2} \mathrm{CH}_{2} \mathrm{O}\right)_{12}\right)_{3} \mathrm{~B}$ (M550$\mathrm{B} 100$ ) and a lithium salt (lithium trifluoromethanelsulfon imide, LiTFSI) was obtained. It has high thermal stability up to $350^{\circ} \mathrm{C}$ and possesses most favorable ionic conductivities, $10^{-4} \mathrm{~S} \cdot \mathrm{cm}^{-1}$ at room temperature and $10^{-3} \mathrm{~S}$. $\mathrm{cm}^{-1}$ at $60^{\circ} \mathrm{C} .{ }^{3)}$

It is reported that salts containing large organic anion reveal higher ionic conductivity. ${ }^{4}$ ) This type of salts in polymer system leads to lower crystallinity, higher conductivity as results of low anion transference number. ${ }^{5}$ ) Therefore, in order to improve the electrochemical characteristics of obtained SPE, this study concentrates on the preparation and the investigation of the electrochemical properties of DSPE with additives of novel organic lithium salts.

\section{Experimental}

Two new lithium salts, lithium dodecylsulfonate $\mathrm{CH}_{3}$ $\left(\mathrm{CH}_{2}\right)_{11} \mathrm{OSO}_{3} \mathrm{Li}$ named as $\mathrm{LiX}$ and lithium triethyleneglycol-1-dodecylether-10-sulfonate $\mathrm{CH}_{3}\left(\mathrm{CH}_{2}\right)_{11} \mathrm{O}\left(\mathrm{C}_{2} \mathrm{H}_{4} \mathrm{O}\right)_{3}$ $\mathrm{SO}_{3} \mathrm{Li}$ named as $\mathrm{LiY}$ were tested as an additive to DSPE. The LiX was obtained by ion exchange reaction of sodium triethyleneglycol-1-dodecylether-10-sulfonate $\mathrm{CH}_{3}$ $\left(\mathrm{CH}_{2}\right)_{11} \mathrm{OSO}_{3} \mathrm{Na}$ (Persoft ${ }^{\circledR} \mathrm{SP}$ ) supplied from NOF Corporation with equimolar $\mathrm{LiCl}$ in ethanol. Since $\mathrm{NaCl}$ formed by the ion exchange reaction is insoluble in ethanol, al- most all the formed $\mathrm{NaCl}$ is precipitated from the ethanol solution. After the filtration of the solution, the LiX was precipitated from the solution along the evaporation of ethanol. The LiY was also obtained by the same procedure. The obtained lithium salts were re-crystallized from ethanol three times and dried under vacuum at $110^{\circ} \mathrm{C}$ for $12 \mathrm{~h}$. The ICP analysis revealed that the prepared lithium salts did not contain sodium ion. Polymer electrolytes were prepared by conventional solvent casting technique in an Ar filled glove box. At first, PME-4000 (15 wt \%), PDE-600 (15 wt\%) and M550-B100 (70 wt\%) were dissolved into acetonitrile. Appropriate molar ratio of lithium salts was added to solution so as to adjust $\mathrm{EO}$ units: $\mathrm{Li}=$ 8:1 by molar ratio. This solution was poured into Teflon pool. After the evaporation of acetonitrile, polymerization was accomplished by heating the pool at $110^{\circ} \mathrm{C}$ for $2 \mathrm{~h}$ under vacuum. Formed polymer film in the pool was cut into disk form with $1.0 \mathrm{~cm}$ diameter and $0.12 \mathrm{~cm}$ thickness in order to test electrochemical properties.

The impedance measurements were carried out using SUS304 cell $(1.0 \mathrm{~cm} \phi$ diameter $)$ on a computerinterfaced HP4192A impedance analyzer over the frequency ranges $5 \mathrm{~Hz}-13 \mathrm{MHz}$ in the temperature range from 25 to $110^{\circ} \mathrm{C}$. The conductivity of the polymer electrolyte film was calculated as inverse of the bulk resistance $R_{\mathrm{b}}$ value. Thermal property of the polymers was evaluated by thermo-gravimetric analysis using TG-DTA apparatus (TGD-9600, Shinku-riko) at a scan rate of $10^{\circ} \mathrm{C} \cdot \min ^{-1}$ in $N_{2}$ atmosphere.

\section{Results and Discussion}

Figure 1a and Fig. 1b show the temperature dependence of ionic conductivity of the polymer electrolytes containing LiX and LiY, respectively. It can be seen that the conductivity of the electrolyte based on pure sulfonates is lower than that for the system containing only LiTFSI. It has been reported that LiTFSI exhibits high ionic conductivity compared with other lithium salts be- 

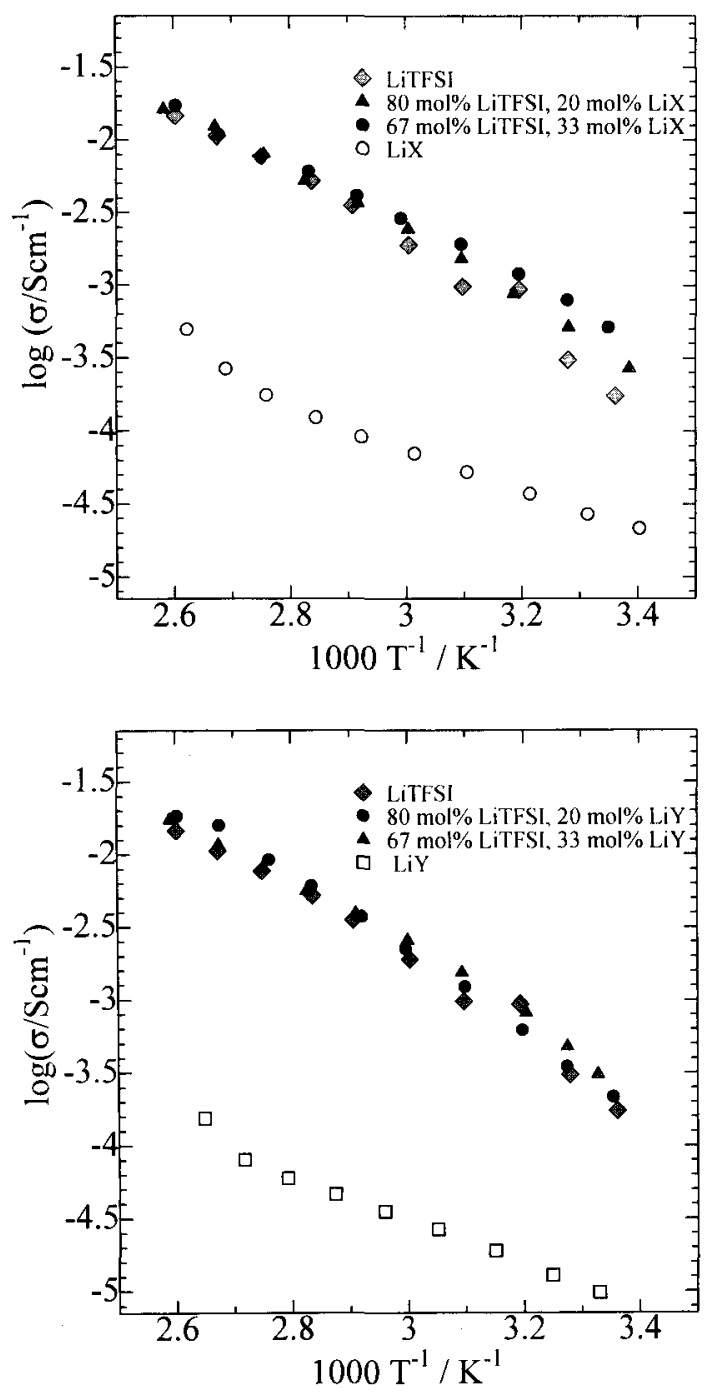

Fig. 1 Comparison of conductivity values for DSPE based systems with and without addition of (a) LiX and (b) LiY.

cause of delocalization of negative charge on $\mathrm{TFSI}^{-}$anion. ${ }^{6)}$ On the other hand, LiX and LiY would not completely dissociate due to the localization of negative charge on sulfonate groups.

It can be seen from Fig. 1a that the addition of the LiX leads to an increase of conductivity for the studied systems from $1.9 \times 10^{-4} \mathrm{~S} \cdot \mathrm{cm}^{-1}$ (for system without $\mathrm{LiX}$ ) to $5.1 \times 10^{-4} \mathrm{~S} \cdot \mathrm{cm}^{-1}$ (with $33 \mathrm{~mol} \%$ of sulfonate) at $25^{\circ} \mathrm{C}$. Only the number of carrier ions cannot explain this tremendous increase. In this system there is a polar sulfonate-group of dodecylsulfonate, which can play a role of coordination center and reduce cation-anion interaction. Therefore a mobility of $\mathrm{Li}^{+}$ion increases. The addition of $\mathrm{LiX}$ also can lead to a reduction of the crystallinity of the host polymer. In the case of LiY, the addition of salt does not lead to the marked change of the conductivity of the parent system. This phenomenon can be explained by considering the decrease of the polarity of anion - cation bond in LiY in the presence of EO groups and a reduction of the dissociation degree. As a result, solubility of LiY in the polymer matrix is lower than that of LiX.

Transference numbers of $\mathrm{Li}^{+}$ion for the studied systems were calculated by the method described in the reference. ${ }^{1}$ For the electrolyte containing LiX, the transference number of lithium ion $t_{+}$improved compared with electrolyte containing only LiTFSI $\left(t_{+}=0.38\right)$ and it is approximately $0.43(67 \mathrm{~mol} \%$ LiTFSI and $33 \mathrm{~mol} \% \mathrm{LiX})$ at room temperature. For the system based on LiY, we could not measure accurate number of this value because of low solubility of this salt.

The differential thermo-gravimetric analysis (DTA) showed that studied systems are thermally stable up to $200^{\circ} \mathrm{C}$.

It should be noted that these salts are surfactants and they are basic materials for producing of soap. Cost of these products is very low, especially compared with cost of the salts used in lithium batteries, e.g. lithium trifluoromethylsulfonyl imide LiTFSI. Despite mentioned advantages, salts studied in this work have a corrosion activity. This property can make it difficult to use these salts in the practical purpose.

The addition of lithium organic sulfonates is a versatile method to improve the electrochemical properties of $\mathrm{Li}$ conducting polymer electrolytes. The conductivity of the parent system has been improved by three times due to the addition of these salts. On this background, it can be concluded that an investigation on this direction is very promising to develop solid polymer electrolytes for the lithium batteries.

\section{Acknowledgments}

We gratefully acknowledged to Mr. S. Yokoyama (NOF Co.) for his assistance in the synthesis of salts. One of authors (Zh.Bakenov) thanks the UNESCO very much. This work was supported by Grant-in-Aid for Scientific Research on Priority Areas (B) (No.740) "Fundamental Studies for Fabrication of All Solid State Ionic Devices" from Ministry of Education, Science, Sports and Culture.

\section{References}

1) B. Scrosati, Lithium Ion Batteries (Eds. M. Wakihara and O. Yamamoto), Wiley-VCH, chap.10 (1998).

2) F.B. Dias, L. Plomp, and J.B. Veldhuis, J. Power Sources, 88, 169 (2000).

3) Y. Kato, S. Yokoyama, H. Ikuta, Y. Uchimoto, and M. Wakihara, Electrochem. Comm., 3, 128 (2001).

4) M. Armand, W. Gorecki, and R. Andreani, Proceedings in the Second International Meeting on Polymer Electrolytes (Ed. B. Scrosati), Elsevier, New York, p.91 (1990).

5) D. Benrabah, D. Baril, J.Y. Sanchez, and M. Armand, J. Chem. Soc., Faraday Trans, 89, 355 (1993).

6) I. Rey, P. Johansson, J. Lindgren, J. C. Lassegues, J. Grondin, and L. Servant, J Phys. Chem. A, 102, 3249 (1998). 